\title{
Festas rurais: mídia, dimensão festiva e impacto social em duas pequenas comunidades do Rio Grande do Sul
}

\author{
Rural Feasts: media, festive dimension and social impact in two small communities in state of Rio Grande do Sul
}

\author{
Jordana Georgin', Cibele Bolzan Scherer² \\ 'Engenheira Ambiental, Universidade Federal de Santa Maria, \\ ${ }^{2}$ Médica Veterinária, Universidade Federal de Santa Maria
}

\begin{abstract}
Resumo
O trabalho teve como objetivo analisar as festividades rurais que ocorrem nos municípios de São Sepé e Caiçara/RS, dando enfoque nos meios midiáticos utilizados e na dimensão que estas festas trazem para as regiões. As festas da comunidade que se estabelecem nestes contextos revelam, por exemplo, uma modalidade de mutirão que permanece viva, evidenciando a organização da comunidade. A respeito da refeição festiva, é a qualidade da comida, servida com capricho e de maneira farta, que exprimirá a consideração para com os convidados. A comida é um elemento que congrega, na medida em que a festa enseja o comer e o beber, apresentando-se, desse modo, o caráter socializante da comida. Estas festas comunitárias envolvem períodos de preparação anteriores, em que os membros das diretorias da comunidade reúnem-se - desse processo fazem também parte os cônjuges e, muitas vezes, as (os) filhas (os). A participação na preparação da festa não se constitui em uma atividade remunerada, todos os produtores rurais trabalham gratuitamente, pela comunidade. Tendo como objetivo alcançar as metas da festa, seja como papel de divulgação, como é o caso dos dois eventos analisados, ou de lucro local.
\end{abstract}

Palavras-chaves: Festas comunitárias; meio midiático; produtor rural.

\begin{abstract}
The work aims to analyze both rural festivities that take place in the cities of Sao Sepe and Rascal / RS, giving a focus on media means used and the extent that these parties bring to the regions. Community festivals that take place in these contexts reveal, for example, a form of collective effort that remains alive, showing the organization of the community. Regarding the festive meal is the quality of food served beautifully and sick way, that express the consideration for the guests. The food is a factor which brings together, in so far as the party gives rise to eating and drinking, presenting thus socializing character of the food. These community parties involve periods prior preparation, in which members of the community boards meet - are also part of this process spouses and often (the) daughters (the). Participation in party preparation does not constitute a remunerated activity, all farmers work for free, by the community. Aiming to achieve the party's goals, either as disclosure of paper as is the case of the two events analyzed, or local income only.
\end{abstract}

Keywords: Community Events; through media; farmers. 


\section{INTRODUÇÃO}

Com as modificações nas formas de produção e relações sociais ocorridas no meio rural brasileiro, especialmente a partir da década de 1980, opções de atividades alternativas no campo são necessárias para a complementação de renda. O turismo rural surge como uma opção de atividade não-agrícola, já que se mostrou com grande potencial para atrair visitantes, notadamente dos grandes centros urbanos. A cultura do homem do campo pode ser vista como um diferencial, assim as festas rurais podem se tornar local de expressão do patrimônio cultural imaterial.

No caso das festas rurais, além do visitante entrar em contato com a cultura local, mesmo com toda a polêmica de transformar a cultura em "espetáculo" (ou seja, manifestações acabam sendo recriadas para servir de produto turístico de determinada região, mesmo não fazendo mais parte da tradição local), a população residente pode passar a valorizar mais seu espaço de vivência (CARVALHO, 2008).

Uma festividade, seja ela rural ou não, é uma modalidade de evento, sendo que o evento, de forma geral, de acordo com Kunsch (2003, p. 385), é "um excelente meio de comunicação dirigida aproximativa" entre todos os púbicos envolvidos. O evento constitui-se como estratégico, pois é planejado, coordenado, organizado, controlado e avaliado em busca de objetivos preestabelecidos pelos seus organizadores. Um evento, quando bem organizado e, principalmente, quando bem divulgado, torna-se eficiente forma de elevar, manter ou recuperar conceito (CESCA, 1997).

Desta forma, a festa é um espaço de adensamento de trocas simbólicas, já que articula os diferentes atores que dela participam, marcando a importância dos lugares associados às tradições vernaculares e à história espacial (FERREIRA, 2006).

Conforme Bezerra (2008), por intermédio das festividades, são celebradas as experiências e as representações identitárias locais, sendo uma das formas de afirmação das particularidades/singularidades, implicando numa redefinição das espacialidades e temporalidades das formas de festejar. É durante as festas que as pessoas atingem um alto grau de sociabilidade, ao mesmo tempo em que mostra a relação que estas têm com o seu meio, refletindo o que pensam e sentem, valorizando, mais ou menos, certos lugares.

O presente artigo tem como objetivo descrever ambas as festividades rurais que ocorrem nos municípios de São Sepé e Caiçara, dando enfoque nos meios midiáticos utilizados, na dimensão que estas festas trazem para as regiões e, consequentemente, nos impactos sociais gerados nas comunidades.

\section{MATERIAIS E MÉTADOS}

\subsection{Localização da comunidade de Caiçara/RS}

É um município que faz parte da Microrregião de Frederico Westphalen, localizada no norte do estado. A cerca de $450 \mathrm{~km}$ da capital Porto Alegre, possui uma área de $189,45 \mathrm{~km}^{2}$ e sua população estimada é de 5.184 habitantes, sendo que cerca de 3.467 habitantes vivem no meio rural, a maioria pequeno produtor com até 10 hectares (IBGE, 2012). Por se tratar de uma região bastante acidentada, a principal atividade econômica do município é o plantio de fumo, porém, devido aos problemas de saúde que esta atividade estava trazendo aos produtores, a prefeitura vem tentando mudar a atividade econômica. Com isso, a criação de gado de corte vem aumentando constantemente na região (Figura 1). Por esse motivo surgiu a necessidade de atividades de divulgação no mercado consumidor.

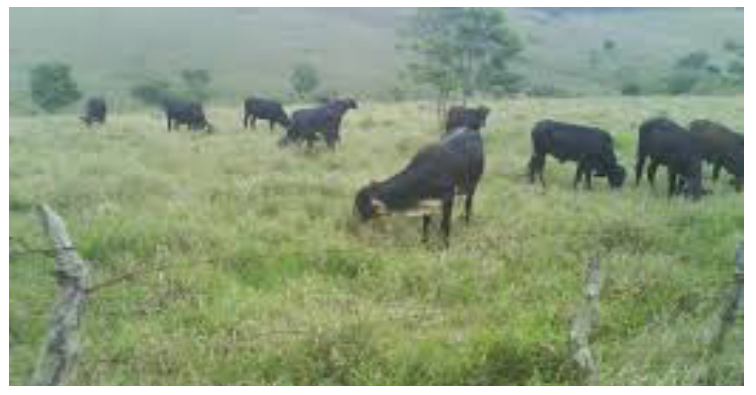

Figura 1 - Produção de gado de corte no município de Caiçara/RS

Fonte - Autora 
A cada seis meses a cidade realiza o jantar do Boi Gordo, onde a própria comunidade local se prontifica em trabalhar (Figura 2), tendo a apoio da prefeitura e da cooperativa. Todos os dados levantados para ambos os eventos foram feitos por meio da participação na elaboração do evento junto à comunidade.

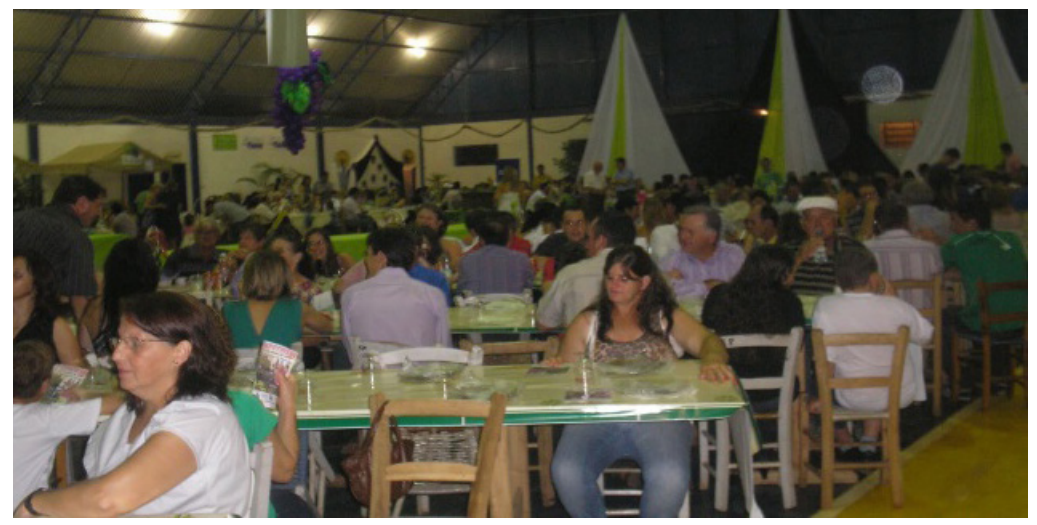

Figura 2 - Jantar do Boi Gordo em sua quinta edição.

Fonte - Autora

\subsection{Localização da comunidade de São Sepé/RS}

O município de São Sepé está localizado na Região Central do Rio Grande do Sul, distante $270 \mathrm{~km}$ da capital gaúcha, Porto Alegre. Possui uma economia baseada nas atividades agropecuárias, com destaque para o arroz, a soja e o milho na agricultura e a criação de gado de corte e ovinos na pecuária. A área total do município compreende $2188.832 \mathrm{~m}^{2}$ e uma população estimada em 23.798 habitantes. Destes, aproximadamente 21\% reside no meio rural (IBGE, 2015).

Assim como a ovinocultura em um cenário geral, São Sepé viveu o auge da criação de ovelhas no século passado, vindo esta a decair com a inserção da lã sintética. No entanto, transpondo para o nível cultural, nunca houve perda total do rebanho ovino, sempre estando presente, mesmo que em números mais baixos.

Preocupados com a situação produtiva da carne ovina no cenário nacional e, principalmente, a nível estadual, os quarenta produtores associados lançaram mão da estratégia de dar visibilidade à carne ovina através da promoção do I Jantar do Cordeiro, onde os participantes do evento contaram com a oportunidade de degustar a carne ovina nos seus mais diversos preparos e, desta forma, promovê-la como um produto digno de ser valorizado na mesa dos brasileiros.

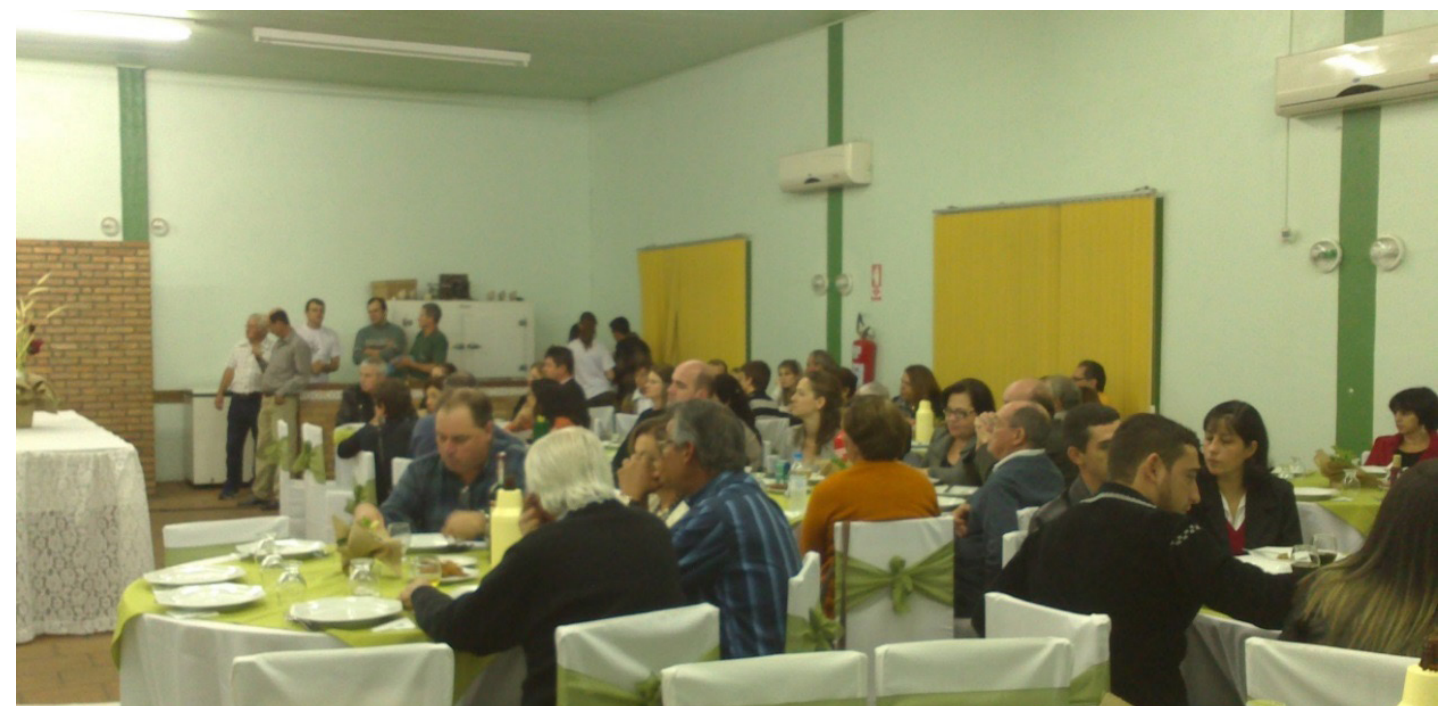

Figura 3 - I Jantar do Cordeiro.

Fonte - Autora. 


\section{RESULTADOS E DISCUSSÕES}

\subsection{Comunicação e Mobilização Social}

A ovinocultura vem sendo promovida no município de São Sepé há algum tempo. Para tanto, programas especiais de fomento na produção ovina como o Juntos para Competir, do SENAR/SEBRAE, vieram até o município para mobilizar os produtores que aqui mantém sua produção. E, no anseio de uni-los para fortalecer a comercialização e a valorização da cadeia ovina, em abril de 2013, fundou-se a Associação Sepeense de Ovinocultores, a ASO.

Programas sociais que incentivam a produção rural local são de suma importância. Assim como ocorre em São Sepé, no município de Caiçara/RS, ocorre a festa do boi gordo, a cada seis meses. O evento foi criado pela comunidade local, objetivando incentivar o consumo da carne produzida pelos produtores. A criação de boi de corte na região vem aumentando cada vez mais, visto que os agricultores estão substituindo o plantio de fumo, o qual é muito prejudicial a saúde, pela criação de gado de corte. Desde então, a prefeitura local estabeleceu um acordo com a cooperativa regional, Cotrifred, a qual vem comprando os animais prontos para o abate. Por se tratar de uma região com relevo bastante acentuado, as terras tornam-se bastante restritas para o uso e, por esse motivo, o incentivo dessa nova atividade é muito importante, tendo em vista o custo inicial que o próprio produtor teve ao mudar a sua fonte de renda.

Para entidades como esta, Henrique (2009) salienta que busca-se formas diferentes de lidar com organizações que se orientam por valores distintos e que podem, por isso mesmo, buscar instrumentos diferentes, mesmo que inseridos numa lógica econômica que as forcem a se orientarem para o mercado. O autor vai além ao sustentar, no atual contexto, que a ideia básica da aplicação prática do conceito marketing, para organizações que não visam lucro, dá sinais inequívocos de ter atingido os seus limites, uma vez que se mostra incapaz de promover um salto qualitativo esperado com a atuação coletiva. Por outro lado, a visão tradicional dos públicos como unidades funcionais pouco dinâmicas vai cedendo lugar a uma noção de agrupamentos em forma de rede, essencialmente flexíveis, que precisam ser compreendidas como complexos sistemas de relacionamento.

Preocupados com a situação produtiva da carne ovina no cenário nacional e, principalmente, a nível estadual, os quarenta produtores associados lançaram mão da estratégia de dar visibilidade à carne ovina através da promoção do I Jantar do Cordeiro, onde os participantes do evento contaram com a oportunidade de degustar a carne ovina nos seus mais diversos preparos e, desta forma, promovê-la como um produto digno de ser valorizado na mesa dos brasileiros. No caso da cidade de Caiçara, o principal objetivo do evento era promover a marca local da carne, para, assim, incentivar a compra do produto nas cooperativas locais.

Este tipo de abordagem possibilita, ainda, lidar com a questão fundamental de manter os sujeitos motivados e interessados em preservar seu vínculo fundamental, uma vez que os produtores foram os responsáveis pela organização de todo o evento. Isso só ocorre a partir de uma profunda convicção sobre o valor da causa e a manifestação de sua coerência no cotidiano, de tal forma que os próprios sujeitos sejam chamados a pensá-las e concretizá-las.

Além disso, o fator cultural é determinante para que estes produtores permaneçam na ovinocultura e o que também estimula a decisão de participar. Esta questão está diretamente ligada à experiência histórica de um povo e à sua tradição em relação a uma consciência participativa, o que a evidencia para a mudança social.

Segundo Mafra (2006), significados possíveis do verbo mobilizar são os de "dar movimento", "pôr em movimento ou em circulação". É relevante observarmos que, quando projeto e movimentos lutam por determinadas causas, há um desejo de "movimentar" as estruturas, os significados, os entendimentos acerca de algumas questões, neste caso, a promoção da cultura de um povo que luta pela sua produção e que a mesma ganhe proporções maiores de comercialização.

Por buscar a efetividade, deve-se dar atenção especial a uma comunicação de menor cobertura, mas de maior impacto. É necessário um esforço permanente para colocar as questões principais no campo dos valores, dos elementos simbólicos com os quais as comunidades operam, em constante atenção para com os múltiplos significados que orientam a vida das comunidades. Esforço tal que a ASO buscou para dar ação e suas lideranças empreenderam estrategicamente.

Henrique (2009) é enfático ao afirmar que as pessoas precisam sentir-se como parte do movi- 
mento e abraçar verdadeiramente sua causa. Sendo a participação uma condição intrínseca e essencial para a mobilização, a principal função da comunicação é gerar e manter vínculos entre os movimentos e seus públicos, por meio do reconhecimento da existência e da importância de cada um, e do compartilhamento de sentidos e de valores. Para tanto, o modo como foi conduzido o projeto e a concretização do Jantar teve direção nestas raízes da comunicação, a fim de gerar a corresponsabilidade, que existe quando o público age por se sentir responsável para com o sucesso do projeto, entendendo sua participação como essencial ao todo.

Assim, a comunicação para a mobilização deve se propor a orientar os indivíduos em seus espaços de interação ou mesmo criar ambientes onde as relações e as interações ocorrerão através do diálogo livre entre os sujeitos, e onde o conhecimento será apreendido e reelaborado através dos próprios contextos da comunidade. Entretanto, esta aprendizagem não será simplesmente episódica, difusa ou pontual, mas, sim, estimulada por uma comunicação que estabeleça lugares próprios de interação, superando a pura espontaneidade através da geração de uma referência que direcione a vivência, a troca e a apreensão de novos significados.

A função básica de gerar e manter vínculos dos públicos com o movimento depende. Segundo Henrique (2009), é difundindo informações dirigidas e de massa, dando visibilidade da iniciativa aos diversos atores que, por algum motivo, tenham sido eleitos como potencial. A difusão de informações a respeito do movimento é fundamental para que as pessoas tenham conhecimento de sua existência, conheçam suas propostas, seus objetivos e formem um julgamento sobre ele.

No caso da ASO, há reuniões mensais e, sempre que possível, é promovido dia de campo, palestra e entrevista sobre o andamento da associação, de forma que todos tenham a mesma informação sobre o trabalho realizado. Já em Caiçara, os agricultores recebem, mensalmente, a visita de técnicos da Emater, e a prefeitura local disponibiliza o veterinário para os mesmos, trazendo maiores incentivos e minimizando gastos. Promover a coletivização: a coletivização pode ser alcançada pelo sentimento e a certeza de que não se está sozinho na luta pela mudança, há outros atuando com o mesmo sentido e propósito. Distingue-se da simples divulgação porque há um compromisso com os resultados e espera-se que as pessoas não apenas tomem conhecimento da informação, mas também incorporem-na de alguma forma, utilizem-na, compartilhem-na e tornem-se, elas próprias, fontes de novas informações (Henrique, 2009).

A circulação de informações legitima as ações das pessoas, conferindo-lhes reconhecimento, conectando-as umas às outras pelo sentimento de pertinência a um grupo com interesses comuns. Esta realimentação se dá, principalmente, pela constante proposição de agendas comuns para a atuação dos integrantes e pela geração de um fluxo comunicativo em que se possa visualizar a trajetória e suas conquistas, de forma a orientar os atores e promover a continuidade das ações e dos resultados. Para fornecer elementos de identificação com a causa e com o projeto mobilizador, foi elaborado um logotipo que identificasse a associação. (Henrique, 2009).

É o sentimento de corresponsabilidade que garantirá, a qualquer que seja a causa, que cada participante seja considerado um beneficiário de sua própria ação, seja esse benefício compreendido de forma direta, podendo ser apropriado pelo próprio participante na melhoria de suas condições imediatas, ou indireta, onde se beneficia de uma melhoria geral das condições de vida, seja qual for o alcance.

\subsection{Identificação das mídias utilizadas}

Segundo Manfra (2006), a mídia tem um papel fundamental nas democracias deliberativas, no sentido de ser uma instância privilegiada para gerar visibilidade e, com uma força simbólica considerável, conferir existência pública a temas que antes poderiam não ser problematizados com tamanho alcance e audiência.

Os recursos da mídia e da comunicação estratégica, em processos de mobilização social, representam usos fundamentais aos projetos, no sentido de gerar visibilidade aos temas, provocar um debate público para (re) definir questões e promover o engajamento coletivo dos sujeitos. Tornar um tema visível é, antes de tudo, conferir-lhe existência. E essa é uma das condições para que um processo comunicativo seja estabelecido.

A Mídia Primária é compreendida como o meio de comunicação, para o ser humano, mais primitivo e essencial para o convívio em sociedade. É preciso salientar, também, que só é possível 
através da presença de emissores e receptores em um mesmo espaço físico ao mesmo tempo: trata-se, portanto, de uma troca informacional em tempo real.

Como mídia primária, foi criado um espaço de visibilidade presencial compartilhado pelos indivíduos da Associação Sepeense de Ovinocultores, através da participação na 39a Expofeira Regional de São Sepé, onde a mesma havia um estande de visitação aberta ao público, no qual interagiram divulgando o trabalho da associação e realizando o convite para o I Jantar do Cordeiro com os visitantes da feira. Já no município de Caiçara, ela ocorre por meio dos próprios agricultores locais, por meio de visitas aos comércios da cidade, juntamente com o uso da mídia secundário, que, ao mesmo tempo, fornece folders, os quais são divulgados na prefeitura local e nas cooperativas. Além disso, um logotipo usado como adesivo nos carros vem chamando a atenção, o qual remete à frase: eu consumo Boi Gordo.

Esta mídia secundária ocorre quando apenas o emissor faz uso de um suporte para transmitir sua mensagem. Logo, todo o objeto que servir para veicular uma mensagem passa a ser mídia, desde suportes para escrita, com livro, até as vestimentas e artigos de moda, que agregam significados aos indivíduos que fazem uso dos mesmos.

Para o jantar do cordeiro foi utilizado três veículos de mídia secundária para divulgação. Primeiramente, foram feitos 500 folders para serem distribuídos durante a Expofeira Regional, em outubro de 2013. Após esta divulgação, a associação ganhou 13 novos associados. Como material de apoio, foram confeccionadas 20 camisetas com o enunciado do Jantar e compradas pelos associados que trabalharam durante o evento, de modo a padronizar. Também foram vendidas ao público em geral.

A principal mídia secundária, a nível local de repercussão, para os dois eventos foi através da rádio $\mathrm{AM}$ dos municípios, onde foi realizada uma entrevista com integrantes da diretoria de ambos os eventos. As entrevistas foram realizadas em programas que possuem grande repercussão local. Assim, o público atingindo foi não só o de ambos os municípios, como também de cidades vizinhas. Além destas mídias, houve, também, um espaço de visibilidade midiático massivo pela internet, através da rede social Facebook, com alcance superior aos outros identificados.

\subsection{Dimensão Festiva: I Jantar do Cordeiro e Jantar do Boi Gordo}

Manfra (2006) identifica três estratégias comunicativas: Dimensão espetacular; Dimensão festiva; e Dimensão argumentativa.

A Dimensão Festiva foi melhor relacionada com o objetivo proposto do I Jantar do Cordeiro. No entanto, o próprio autor defende que, em determinados momentos, pode-se identificar a presença das três dimensões isoladamente ou misturadas quando analisa-se um evento com vistas ao social.

Situações de festa e de celebração são muito comuns em projetos de mobilização social. Nesses momentos, os sujeitos são convidados a participar de redes de sociabilidade e a estabelecer um convívio "corpóreo", motivados por atos de comemoração em relação à causa. A função revigorante da festa representa uma força no sentido contrário ao da dissolução social: uma espécie de "eletricidade" decorre da aproximação dos indivíduos reunidos em um propósito festivo, que pode levá-los, em poucos instantes, a um grau extraordinário de efervescência. Esses vínculos intersubjetivos e coletivos nascem e são gerados na comunhão, na "realiança", baseados não em interesses racionais, mas em sentimentos e emoções.

Nas festas, há uma tendência muito forte dos indivíduos de se reunir mais e experienciar situações de vida diferentes do cotidiano. Tal é a especificidade dessas vivências que o homem torna-se outro. É instauradora de uma forma de associação, na qual o destaque é dado pelo estar junto, pelo fato mesmo da relação.

Chama-se a atenção especial para o fato de que as formas se desenvolvem na interação, significa que os atores têm condições de modificar e recriar os elementos presentes nas formas estabelecidas, preservando um grau de espontaneidade que nunca se esgota totalmente. Assim, por mais que indivíduos sigam práticas sociais rotinizadas e padrões institucionalizados de comportamento, eles podem ressignificar as formas de interação, processo esse que pode escapar ao controle administrativo, à regulamentação legal ou ao alcance político. As formas, assim, possuem um caráter dual, são superiores aos atores, mas, ao mesmo tempo, a eles submissas. Isso significa que as ordens sociais dependem da atualização que os próprios indivíduos operam em situações concretas, nos múltiplos interstícios e nichos, de microscópicos a macroscópicos, da vida social. 
Por isso, é interessante entender como as festas, que possibilitam o "estar-junto", a interação quase que por ela mesma, são fundamentais no sentido de promover e potencializar redes de sociabilidade e convivialidade - mesmo sabendo que as festas não representam as únicas forças agregadoras, que unem os indivíduos, mas que, por suas possibilidades de interação, permitem o "estar-junto", uma peculiar e aglutinadora forma de relação entre os sujeitos.

Em termos mais específicos, a festa não pode ser entendida somente como ritual nem como uma simples diversão. Obviamente, toda festa tem certo aspecto ritual, uma vez que conserva determinada dimensão cerimonial. Mas também não deixa de ser igualmente divertimento. Por isso, é a densidade da festa - seu caráter de efervescência coletiva - e seu caráter extratemporal e extralógico que a tornam peculiar.

Uma das características peculiares das situações festivas é a interrupção do trabalho: a vivência coletiva instaurada nesses movimentos possibilita, ao homem, distrair-se de suas preocupações cotidianas.

Uma distinção importante se impõe: embora a festa seja também um espetáculo, distingue-se dele, pois exige a participação ativa, marcada por esse aniquilamento, por esse abandono de si e na confusão com o outro. É impossível ser apenas espectador de uma festa. Ela impõe participação, leiase relação, o estar-junto.

Desse modo, a dimensão festiva de ações de mobilização social possui características diferentes da dimensão espetacular: mais do que capturar a atenção dos sujeitos, busca envolve-los afetivamente/ sentimentalmente, entende o público como participante das festas realizadas e tem, baseada em laços mais espontâneos de sociabilidade, a convivialidade como modalidade de participação nas relações comunicativas instauradas pelas festas.

É conveniente lembrarmos que, como os projetos desejam provocar processos de debate público e de mobilização social, é imprescindível que eles forneçam argumentos que sustentem suas propostas e que não somente entendam o público como audiência ou como participante de festa, mas também como um conjunto de interlocutores capazes de dividir com ele as responsabilidades pelas mudanças propostas. Dito de outra maneira, tal processo deve possuir, também, eminentemente, um caráter argumentativo.

\subsection{Análise do Impacto Social}

Quando em poucas reuniões ainda feitas pela Associação Sepeense de Ovinocultores, surgiu a ideia de então realizar algo em que pudesse gerar visibilidade à produção ovina do município e que, ao mesmo tempo, gerasse o interesse da apreciação pelo principal produto, a carne, dada vista a dificuldade dos produtores familiares em comercializar sua pequena produção. Assim, solidificou-se o projeto do I Jantar do Cordeiro. Já no município de Caiçara, o evento foi realizado visando incentivar o consumo da carne local, visto que a quantidade da produção aumentou muito depois que houve a troca da atividade econômica local. Para dar andamento ao acordo da prefeitura com a cooperativa local, o consumo nos mercados deveria ser rentável e, como trata-se de um produto novo, a divulgação foi imprescindível.

Conforme anteriormente descrito, as festas que surgem como forma de mobilização social obtiveram grande impacto entre os associados e, também, nas comunidades na qual estão inseridas.

No intuito de trazê-los como corresponsáveis para o evento em São Sepé, houve um primeiro encontro, denominado como Oficina de Cortes de Carne Ovina, ministrada pela Extensionista de Bem-estar Social da Emater juntamente com um chefe. Assim, os produtores puderam aprender desde a retirada dos cortes da carcaça até a elaboração dos pratos que foram servidos no dia do Jantar. Assim, estavam inseridos e responsáveis pelo processo.

Desta maneira, as emoções foram divididas por todos ali envolvidos. Com este engajamento e o vínculo gerado, houve união, busca por patrocínio, trocas de experiência e o desejo de que o produto ali apresentado fosse o melhor marketing. De fato, presenciou-se um evento inusitado e perceptível pela comunidade: houve mobilização. Isso ocorreu pois o evento precisava chamar a atenção não só da comunidade local, mas também das autoridades locais para se ter politicas públicas de incentivos. O jantar do Boi Gordo, por sua vez, era uma atividade que já possuía todo um financiamento e um acordo entre prefeitura e cooperativa, tendo, neste caso, foco na população local e regional.

Com o auxílio da mídia de massa, houve a venda de praticamente todos os ingressos de ambos os eventos. Compareceram autoridades políticas e associadas, os eventos, que antes tinham como 
cunho principal o marketing, puderam proporcionar o encontro da corresponsabilidade, da troca de experiência, vínculos e um espaço de debate.

\section{CONCLUSÕES}

Ambos os eventos tiveram como base uma forte midiatização, tanto primária como secundária, com isso pode-se atingir uma grande massa populacional, o que proporcionará, futuramente, o sucesso das atividades realizadas pelas comunidades de São Sepé e Caiçara, Rio Grande do Sul. O impacto social que ocorreu demonstra a efetividade das mídias na busca pelo desenvolvimento das sociedades descritas, uma vez que eventos deste aporto são clarividentes na transformação dos espaços sociais e econômicos.

\section{REFERÊNCIAS}

BEZERRA, Amélia Cristina Alves. Festa e cidade: entrelaçamentos e proximidades. In: Espaço e cultura, UERJ, RJ, n. 23, p. 7-18, jan./jun. de 2008.

CAMPANHOLA, C.; GRAZIANO DA SILVA, J. Panorama do turismo no espaço rural

brasileiro: nova oportunidade para o pequeno agricultor. Disponível em <http://www.eco.unicamp.br/pesquisa/ NEA/pesquisas/rurbano> Acesso em 20 out 2008. s/p.

CARVALHO, J. A. de S. (org). Festas rurais. Londrina, 2008. Trabalho não-publicado.

CESCA, Cleuza Gertrude Gimenes. Organização de eventos. São Paulo: Summus, 1997.

FERREIRA, M. N. Comunicação, resistência e cidadania: as festas populares. In: Comunicação e Política, v. 24, n. 2, p. 61-71, 2006.

HENRIQUES, M. S. (org). Comunicação e Estratégia de Mobilização Social. Gênesis- Fundação Educacional e Cultural. Gráfica e Editora Dom Bosco. Belo Horizonte, MG. 2009.

Instituto Brasileiro de Geografia e Estatística (BR). Censo Demigráfico 2012. Acesso em 13 de janeiro 2015. Disponível em: http://www.censo2010.ibge.gov.br/index.php.

Instituto Brasileiro de Geografia e Estatística (BR). Censo Demográfico 2010. Acesso em 24 de janeiro de 2015. Disponível em: http://www.cidades.ibge.gov.br/xtras/temas.php?lang=\&codmun=431960\&idtema=90search=rio-grande-so-sul| sao-sepe | censo-demografico-2010:-resultados-da-amostra-caracteristicas-da-populaçao-

KUNSCH, Margarida Maria Krohling. Planejamento de relações públicas na comunicação integrada. São Paulo: Summus, 2003.

MAFRA, R. Entre o espetáculo, a festa e a argumentação: mídia, comunicação estratégica e mobilização social. Belo Horizonte. Autêntica, 192p. 2006.

SANTOS, K. C. O. Estudos dos conceitos fundamentais da teoria da mídia de Harry pross: uma teoria dos multi meios. Pontifícia Universidade Católica de São Paulo, São Paulo. 2009. 